\title{
Correction to: Automatic quantification of porosity using an intelligent classifier
}

\author{
Ángel Iván García Moreno ${ }^{1}$
}

Published online: 11 December 2019

(C) Springer-Verlag London Ltd., part of Springer Nature 2019

\section{Correction to: The International Journal of Advanced}

Manufacturing Technology

https://doi.org/10.1007/s00170-019-04067-5

Acknowledgments

Acknowledgments are due to program CátedrasCONACYT (National Council for Science and Technology of Mexico) for the support provided by generating research opportunities through the projects num. 730 and num. 57. Thanks are due to the Mexican Space Agency, for financial support through project CONACYT-AEM num. 275781. Also, the author thanks the financial support provided by CONACYT through the Programs Fordecyt (projects 297265 and 296384). Additionally, thanks are due to the CONACYT Consortium in Additive Manufacturing (CONMAD) for the use of experimental facilities for this work.

The online version of the original article can be found at https://doi.org/ 10.1007/s00170-019-04067-5

Ángel Iván García Moreno

angel.garcia@cidesi.edu.mx

1 Center for Engineering and Industrial Development (CIDESI), Av.

Playa Pie de la Cuesta No. 702. Desarrollo San Pablo.,

Quer'etaro, Qro., Mexico 